\title{
Bargaining in a Push Supply Chain System under Partial Cross Ownership
}

\author{
Jiguang Chen \\ School of Management \\ Fudan University \\ Shanghai, 200433, China \\ cjgrace520@sina.com
}

\author{
Qiying $\mathrm{Hu}$ \\ School of Management \\ Fudan University \\ Shanghai, 200433, China \\ qyhu@fudan.edu.cn
}

\begin{abstract}
Supply chain under partial cross ownership (PCO) refers to the dyad in which each one holds part of its partner's shares. In a two-echelon push supply chain under the partial cross ownership, when the operational decisions are bargained, the supply chain is coordinated, and the allocation of the chain profit is dependent on the bargain coefficients and the reserve profits, and independent of the PCO structure: letting the retailer hold part of the supplier's shares doesn't affect the chain efficiency and both players' profits. Similarly, letting the supplier hold part of the retailer's shares doesn't affect the chain efficiency and both players' profits.
\end{abstract}

Keywords-System engineering; Supply chain; Push; Bagaining; partial cross ownership

\section{INTRODUCTION}

Supply chain, or more exactly, supply networks under our current advanced, fast-changing and complicated cuttingedge technology, is a commonly studied system in the academic field of system engineering and optimization. Questions ranging from supply system design, reliability, reconfiguration, to efficiency-enhancing are investigated. In this paper we focus on how to increase the supply chain efficiency, which is a challenge of a great practical value. Specifically, we dedicate to how to use incentive mechanism, i.e., the profits, the wholesale price, to increase the supply chain efficiency.

Motivated by current state-of-art practices, we adopt a two echelon supply chain, that is, the inventory risk is pushed from upstream to the downstream. Different from traditional two echelon supply chain consisting of two independent players, we explore a partial cross ownership (PCO) setting, which is a terminology from law, and refers to the case of two firms hold each other's shares, with one firm holding shares of the second one unidirectionally as a special case.

Luzhou Laojiao, a Chinese wine giant issued additional shares in a private placement with its retailers in 2010, and then its retailers hold a share in the wine giant (Chen and $\mathrm{Hu}$ 2012). Other examples of industries that feature partial cross ownerships are given in Chen and $\mathrm{Hu}$ (2012), ranging from the U.S. automobile industries, the global airline industry, the Dutch Financial Sector. Though popular in practice, the impact of PCO on the operation of firms is little studied. Past studies on PCO are mainly from the field of accounting, economics, finance and law; see the literature part of Chen and $\mathrm{Hu}$ (2012). The research on PCO of vertical partners in supply chain management is very rare, we are the first one to cover this issue under bargaining to our knowledge. Without the PCO, the supply chain under a wholesale price is well investigated, see Lariviere (1999), Lariviere and Porteus (2001), Cachon (2003) and Cachon (2004). Chen and $\mathrm{Hu}$ (2012) consider a general framework to analyze the effect of PCO under various supply chain structures given a classic newsvendor stylized random demand. They analytically show that under the PCO, the chain efficiency is independent of how much the percentage of the leader's shares held by the follower, while increases with the follower's shares held by the leader. The profits of the chain and the leader increase under PCO, while the follower's profit not necessarily increases.

However, it is unclear do these results hold when the operational decisions are bargained instead of being set by an individual firm. In this paper, we investigate does PCO change the bargain solution when the wholesale price and order quantity are bargained.

Our analysis shows that letting the retailer hold part of the supplier's shares doesn't affect the chain efficiency and both players' profits. Similarly, letting the supplier hold part of the retailer's shares doesn't affect the chain efficiency and both players' profits. That is, under bargaining the push supply chain is coordinated, and the allocation of the chain profit is dependent on the bargain coefficients and the reserve profits, and independent of the PCO structure.

The rest of the paper is organized as follows. Section 2 first gives a brief description about the push supply chain, followed by section 3 on the analytical work on the chain performance under bargaining. Section 4 is a concluding section.

\section{A PUSH CHAIN UNDER PCO}

The push supply chain studied here consists of one supplier and one retailer. The supplier first determines a wholesale price $w$ under which the supplier can produce as many as the retailer wants. Next, the retailer, facing an exogenous retail price $p$ and stochastic demand, submits an order quantity $\mathrm{y}$. Then, the supplier produces $y$ units at a constant marginal cost $c$ to fill the retailer's order. To avoid the problem to be trivial, we assume $p>_{c}$. At last, the retailer receives the order quantity $y$ at the start of the selling season and bears the inventory risk of oversupply when the realized demand is low (Cachon 2004). Unmet demand is 
lost. To make our mathematical analysis simple to capture the essential effect of the PCO, we assume that any unsold inventory has no salvage value. In fact, a nonzero salvage value, whether a positive or negative one, does not change all our conclusions below.

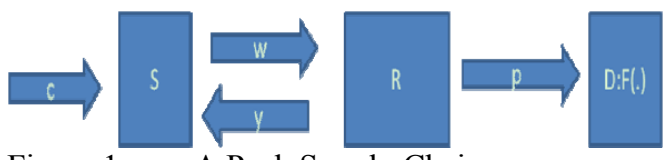

Figure 1 A Push Supply Chain

Suppose the random demand has the distribution function (d.f.) $\mathrm{F}(\mathrm{x})$ and the probability density function $\mathrm{f}(\mathrm{x})$ with support $[0,+\infty)$. In Chen and $\mathrm{Hu}(2012)$, they assume that $\mathrm{F}(\mathrm{x})$ is strictly IGFR (increasing generalized failure rate), i.e., $g(x):=x f(x) /(1-F(x))$ strictly increases with $y$, and that $f(x)$ is continuously derivative for mathematically simple. Here, our results don't need this IGFR assumption, which applies to more generous cases than Chen and $\mathrm{Hu}$ (2012).

Using the same framework introduced by $\mathrm{Chen}$ and $\mathrm{Hu}$ (2012), we consider two firms, named firm A and firm B. Firm A holds $\tilde{1}$. percentage of the retailer's shares and percentage of the supplier's shares, while firm B has. . percentage of the retailer's shares and $\tilde{1}$. percentage of the supplier's shares. Note that Chen and $\mathrm{Hu}$ (2012) assume that $\sim$ and $\sim$. Here, we generalize their work, and don't need this assumption, because when , the supplier's share is equally split between two firms $\mathrm{A}$ and $\mathrm{B}$, and the wholesale price and order quantity are determined through bargain instead of decided solely by a self-interested firm, and similarly for $\sim$. When and (or and $\sim$ ), firm A (or B) holds the dominant shares in both the supplier and the retailer, and so is in charge of both in the two-dyad channel. Our bargaining framework can still by applied, and clearly this cross ownership structure leads the supply chain to be a centralized one, under the chain achieves the maximum profit with an order quantity $y^{c}$ satisfying $1-F\left(y^{c}\right)=c / p$. Finally, $\sim$ and $\sim$ is the same as the case of $\sim$ and

We are more interested in the impact on the operation efficiency of PCO. As firm A is in control of the retailer, for simplicity we call firm A "the retailer" (she). Similarly, we call firm B "the supplier" (he). In the standard financial term, firm $\mathrm{A}$ and firm $\mathrm{B}$ are both parent companies, and we are interested in the profits of both parent companies.

When . and .. the supply chain is the same as without PCO. According to the analysis in Lariviere and Porteus (2001), the equilibrium order quantity $y^{0}$ satisfies $1-F\left(y^{0}\right)-y^{0} f\left(y^{0}\right)=c / p$ while the profits of the retailer and the supplier are, respectively, $\pi_{s}^{0}=\left(p-p F\left(y^{0}\right)-c\right) y^{0}$ and $\pi_{r}^{0}=p \int_{0}^{y^{0}} x f(x) d x$. Here, the IGFR assumption is needed for such a very elegant formulation. However, even without this IGFR assumption, our following result still holds since we only need the existence of $\pi_{s}^{0}$ and $\pi_{r}^{0}$ as disagreement points in the bargaining, and whether they have close form expression doesn't matter for our following analysis.

\section{BARGAINING}

In Chen and $\mathrm{Hu}$ (2012), the supplier acts as the leader in the push supply chain, and they prove that in such a twoechelon push supply chain under the partial cross ownership, letting the retailer hold part of the supplier's shares doesn't affect the chain efficiency and both players' profits.

However, in practice, instead of having one player as the leader, under the PCO both the supply chain partners form an alliance and negotiate the wholesale price and the order quantity. For example, bargaining is often the norm among Toyota and its suppliers, as reported in the classic The machine that changed the world. That is, both the supplier and the retailer may sit together to bargain over a wholesale price $w$ and an order quantity $y$. That is, the operational issue such as the order quantity and the wholesale price will be decided by bargaining. In this section, we consider what will turn out after bargaining, under which both are negotiating the operational issue, since there exist neither first mover nor the second mover. For notational convenience, we refer to the push supply chain as the supply chain in which the inventory is carried by the retailer.

Since the experimental bargaining theory indicates stronger empirical evidence of Nash bargaining theory than any others (Nagarajan and Sosic 2008), we use the Nash bargain solution framework (Nash 1951, Roth 1979) to characterize the bargain when the inventory is pushed from the supplier to the retailer.

Denote by ${ }_{1}$ and the bargain coefficients of the supplier and the retailer, respectively, standing for their bargaining powers in splitting the gained surplus from cooperating together rather than acting in a self-interested way. The larger the coefficient is, the more powerful the supplier/retailer will be, and 1 . refers to the symmetric bargain power case.

Thus, under a wholesale price $w$ and an order quantity $y$, the profits of the supplier and the retailer are, respectively, $\pi_{s}(y, w)=\beta p S(y)+(1-\alpha-\beta) w y-(1-\alpha) c y \quad$ and $\pi_{r}(y, w)=(1-\beta) p S(y)-(1-\alpha-\beta) w y-\alpha c y$. Note to simplify our formulation, when used without confusion, we will omit the independent variable, i.e., $\pi_{s}$ (or $\pi_{r}$ ) for $\pi_{s}(y, w)$ (or $\left.\pi_{r}(y, w)\right)$. Also, denote by $\pi_{c}(y)$ the chain profit under an order quantity $y$, with a maximum $\pi_{c}\left(y^{c}\right)$.

The wholesale price $w$ and the ordering quantity $y$ are jointly decided by both the supplier and the retailer through bargaining, i.e., $\quad \max \left[\left(\pi_{s}-\pi_{s}^{0}\right)^{\gamma_{1}}\left(\pi_{r}-\pi_{r}^{0}\right)^{\gamma_{2}}\right.$ 
where $\pi_{s}^{0}$ and $\pi_{r}^{0}$ are disagreement points, i.e., the reserve profits, of the supplier and the retailer, respectively.

Denote by $y^{*}$ and $w^{*}$ the optimal solution of the equation (1) above, representing Nash bargain solution of the wholesale price and the order quantity, respectively. We have the following proposition on the push supply chain.

Proposition 1: Under the bargain, the supply chain can be coordinated, the equilibrium wholesale price increases with both and, while both the equilibrium order quantity, the profits of both players and the chain are independent of and , i.e., the PCO structure.

\section{Proof:}

The first order condition of the objective (1) above leads to $\gamma_{1}\left(\pi_{s}-\pi_{s}^{0}\right)=\gamma_{2}\left(\pi_{r}-\pi_{r}^{0}\right)$ and

$$
1-F\left(y^{*}\right)=c / p \text {. }
$$

Thus, $y^{*}=y^{c}$, and so the supply chain is coordinated.

Moreover, the wholesale price

$$
\begin{aligned}
& w^{*}=\frac{1}{1-\alpha-\beta}\left[\pi_{r}^{0}+(1-\alpha) c y^{c}\right. \\
& \left.+\frac{\gamma_{1}\left(\pi_{c}\left(y^{c}\right)-\pi_{r}^{0}-\pi_{\mathrm{s}}^{0}\right)}{\gamma_{1}+\gamma_{2}}-\beta S\left(y^{c}\right)\right] \text {, where } \\
& S(y)=\int_{0}^{y} x f(x) d x+y(1-F(y)) \text { is the expected }
\end{aligned}
$$

sales given an order quantity $y$.

Therefore, two players' profits are, respectively,

$$
\begin{aligned}
& \pi_{s}=\pi_{s}^{0}+\frac{\gamma_{1}\left(\pi_{c}\left(y^{c}\right)-\pi_{r}^{0}-\pi_{\mathrm{s}}^{0}\right)}{\gamma_{1}+\gamma_{2}} \text { and } \\
& \pi_{r}=\pi_{r}^{0}+\frac{\gamma_{2}\left(\pi_{c}\left(y^{c}\right)-\pi_{r}^{0}-\pi_{\mathrm{s}}^{0}\right)}{\gamma_{1}+\gamma_{2}} \text {. It is obvious, by }
\end{aligned}
$$

simply checking the first derivate in , that the wholesale price increases with . Similarly, this wholesale price increases with

This completes the proof.

Therefore, the supply chain is coordinated with maximum chain profit, i.e., $y^{*}=y^{c}$ and the extra gain in the chain profit from the bargain is divided according to the bargain coefficients: ${ }_{1} / . \mathrm{C}_{1}+\ldots$. percentage is taken by the supplier and the rest by the retailer. Since the chain profit is maximized, by proper allocating the pie both can enjoy a win-win than acting in a self-interested way. Obviously, both partners' profits are independent of either or .
In addition, $y^{c}$ is a constant indepenent of either ..thus the first derivatives of $y^{*}$ with respect to both and are 0 , which implies that the equilibrium order quantity under bargain is independent of either or . The reason is that each takes into account the other's response.

In summary, Proposition 1 says that for the push supply chains, bargain can make the supply chain coordinated, and the allocation of the chain profit is dependent on the bargain coefficients and the reserve profits, and independent of the PCO structure. Comparing our Proposition 1 above with the result found in Chen and $\mathrm{Hu}$ (2012), we conclude that the effect of PCO on the equilibrium is quite different. Under bargaining PCO has no effect on the supply chain performance. Hence, PCO has a complex effect on the chain, depending on the decision structure of the chain.

\section{CONCLUSION}

Our model is a first step in studying issues related to the partial cross ownership in a push supply chain under bargaining. Our quantitative analysis shows that the result of Chen and $\mathrm{Hu}$ (2012) doesn't holds when the operational decisions are made by bargaining. Thus, we enrich the current research on PCO.

Future research can, for instance, relax some of our assumptions such as a price-setting retailer. It can also help to check in detail the effect of partial cross ownership in an asymmetric information setting.

\section{ACKNOWLEDGEMENT}

This research is supported in part by the National Natural Science Foundation of China under grants 70971023 and 70832002 .

\section{REFERENCE}

[1] Cachon, G. P. 2003. Supply chain coordination with contracts. A. G.de Kok, S. C. Graves, eds., Handbooks in OR $\ \&$ MS. Elsevier..

[2] Cachon, G. P. 2004. The allocation of inventory risk in a supply chain: push, pull, and advance-purchase discount contracts. Management Sci. 50(2), 222-238..

[3] Chen, J., Q. Hu. 2012. Supply Chain under Partial Cross Ownership. Working Paper.

[4] Lariviere, M. 1999. Supply chain contracting and coordination with stochastic demand. S. Tayur, M. Magazine, R. Ganeshan, eds. Quantitative Models for Supply Chain Management. Kluwer.

[5] Lariviere, M., E. Porteus. 2001. Selling to the newsvendor: An analysis of price-only contracts. Manufacturing Service Oper. Management 3(4), 293-305..

[6] Nagarajan, M., Sosic, 2008. Game-theoretic analysis of cooperation among supply chain agents: Review and extensions. European Journal of Operational Research 187, 719-745.

[7] Nash, J., 1951. Noncooperative games. The Annals of Mathematics, 54, 286-295..

[8] Roth, A., 1979. Axiomatic Models in Bargaining. Springer-Verlag.

[9] Womack, J., J. Daniel, R. Daniel. 1991. The Machine that Changed the World. New York: Harper Perennial. 